\title{
Congenital Color Vision Deficiency (CVD) in Children Living in High Altitudes of Nepal
}

\author{
Sushil $\mathrm{K}^{1 *}$ and Mainalee Mandira ${ }^{2}$ \\ ${ }^{1}$ Department of Physiology, Kathmandu Medical College and Teaching Hospital, Nepal \\ ${ }^{2}$ Community Social Work, Nepal
}

\begin{abstract}
Background: It has shown that congenital color vision deficiency (CVD) has different prevalence and patterns in various ethnic groups and geographical areas. Perception of color have significant role in routine daily life. The children with color vision defects may have problems in detecting colors in schools, color posters and slides which may lead to failure in exam as well as in the daily learning activities. So, this present study is aimed to find out the prevalence of CVD in children living in high altitudes of Nepal.
\end{abstract}

Methods: A total of 423 children including 217 males and 206 females between ages 11-15 years were examined for congenital CVD in children of high altitudes (2500meter above sea-level) of Sindhupalchowk and Dolakha districts of Nepal. Each subject was shown the plates of Ishihara for color vision under normal day light at distance of $75 \mathrm{~cm}$ and the duration given for them to see was 5 seconds.

Results: Children's color vision was tested using Ishihara's 38 Plates edition. Among 217 boys, 24 (11.05\%) were color deficient. Among 206 girls, 5 (2.42\%) were color deficient.

Conclusion: The trends of color vision deficiency in high altitudes showed the need of more and more research on CVD in children and make them aware about the problem that might be faced by them in near future.

Keywords: Ishihara's charts (Plates); Color vision deficiency; High altitudes

\section{Introduction}

The role of color and normal color vision has great effect in daily life. Colors have three components: hue, intensity and saturation [1]. It has been seen that most of the color vision defects are congenital. Red-green deficiency which is X-linked has the highest incidence in the population. Congenital color vision deficiency (CVD) is the deficient in perceiving color differences under normal situations. The occurrence of congenital color blindness results either from deviations or deficient in the absorption spectrum of photopigment [2]. The color-blind people are not actually color blind, but are color deficient, so, color vision deficiency (CVD) is the actual term that should be used for color blind people which was named after John Dalton [3]. The discrimination of color in humans depends on uneven stimulation of red, green and blue cone types to lights of different wavelengths. Color vision for normal human is based on the presence of three unique types of receptors which response to light in the retina at wavelengths 420,530 and 560 $\mathrm{nm}$ which are short, middle and long respectively [4]. When a particular color receptive cone is absent from the eye, the person is unable to distinguish same color from other color. Expectation and memory are among factors that influence the colors actually perceived $[5,6]$. Color is routinely used to convey information and findings extensively in the educational system across the globe. Currently, there are no treatments for congenital color vision defects. However, studies showed that early detection of these defects may help children adjust better at school, daily life functioning and may help them understand their limitations of their work [7].

\section{Methods}

After obtaining ethical clearance, a cross sectional study was conducted in children living in high altitudes of Nepal. Informed written consent in Nepali language was taken before gathering the data. The study was done in July-September 2017. A total of 423 children aged 11-15 years (Both males and females) were evaluated for congenital CVD by Ishihara color plates. The children were selected by purposive sampling method. Only the children interested and intending to be evaluated were enrolled in this present study. The screening was done by showing complete plates of Ishihara's plates under day light conditions at distance of $75 \mathrm{~cm}$ to each child. Time allowed to each plate was not given be more than 5 seconds. The type of color blindness was interpreted and evaluated with the help of key provided and as recommended by Ishihara [8-10]. Evaluation and interpretation of the plate was done to detect the normality of color vision and also the type of color deficiency.

\section{Results}

In this study 423 children (Boys 217, girls 206, age 11-15 years), residing in the high altitudes (Above $2500 \mathrm{~m}$ ) of sindhupalchowk and Dolakha districts of Nepal were evaluated and the incidence of color vision deficiency among the study subjects showed higher prevalence in male children living in high altitudes. Out of total 217 boys, 24 (11.05\%) were color deficient (Figure 1). Among 206 girls, 05 (2.42\%) were color deficient. Among the color deficients, 09 were deuteranopia, deuteranomaly (15) and protanomaly (05) (Table 1 and Figure 2).

*Corresponding author: Dr. Sushil Kharel, Department of Physiology, Kathmandu Medical College and Teaching Hospital, Nepal, Tel: +977 1-4476152; E-mail: drsushilkharel@gmail.com

Received November 15, 2017; Accepted November 24, 2017; Published November 28, 2017

Citation: Sushil K, Mandira M (2017) Congenital Color Vision Deficiency (CVD) in Children Living in High Altitudes of Nepal. J Mol Genet Med 11: 306 doi:10.4172/1747-0862.1000306

Copyright: @ 2017 Sushil K, et al. This is an open-access article distributed under the terms of the Creative Commons Attribution License, which permits unrestricted use, distribution, and reproduction in any medium, provided the original author and source are credited 


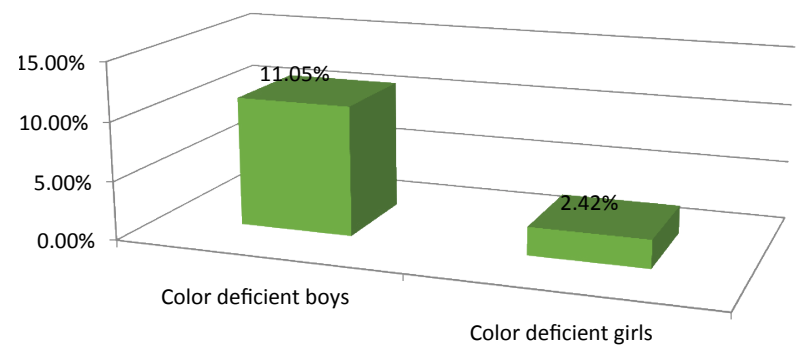

Figure 1: Sex-wise percentage distribution of color vision deficiency (CVD) among the study population $(\mathrm{N}=423)$.

\begin{tabular}{|c|c|c|c|c|c|}
\hline Subjects & $\begin{array}{c}\text { Normal color } \\
\text { vision }\end{array}$ & $\begin{array}{c}\text { Color } \\
\text { deficient }\end{array}$ & $\begin{array}{c}\text { Deuteran- } \\
\text { opia }\end{array}$ & $\begin{array}{c}\text { Deuter- } \\
\text { anomaly }\end{array}$ & Protanomaly \\
\hline $\begin{array}{c}\text { Boys } \\
(217)\end{array}$ & 217 & 24 & 07 & 14 & 03 \\
\hline Girls (206) & 206 & 05 & 02 & 01 & 02 \\
\hline $\begin{array}{c}\text { Total } \\
(423)\end{array}$ & 423 & 29 & 09 & 15 & 05 \\
\hline
\end{tabular}

Table 1: Congenital color vision deficiency among the study subjects $(\mathrm{N}=423)$.

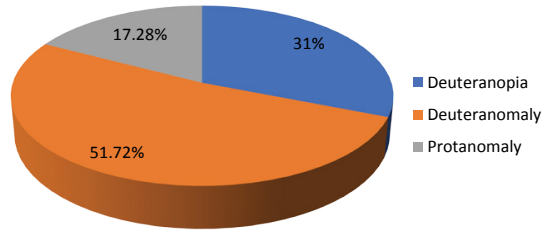

Figure 2: Percentage distribution of different types of color vision deficiency (CVD) among the study population.

\section{Discussion}

The variability of congenital color vision deficiency (CVD) in the different ethnic groups and different geographical areas are of greater interests to the researchers. In our present study done in the high altitudes, the incidence of color vision deficiency among the male children $(11.05 \%)$ were found to be very high than the study done by Niroula and Saha (3.8\%) in the western district of Nepal, Pokhara [11]. In the present study the prevalence of color vision deficiency among female children $(2.42 \%)$ were found to be similar with the study done by Kharel et al. in school children of Bhaktapur, Nepal in 2017 [12] which found it $2.56 \%$. Similarly, in India it was observed that CVD among female children was present in $1.69 \%$ of the study population in a study done by Shah et al. [13]. It was also found that the prevalence of color vision deficient boys was $11.05 \%$ which is similar to $8 \%$ prevalence rate observed in males among in Europeans, permanent residence of UK and the United States [14]. Thus, though the incidence rate for congenital color vision deficiency is almost similar all over the world but it may vary in the incidence rate in different geographical areas and ethnicity. Variation in the incidence in our present study may be attributed to the congenital changes that might have occurred in the permanent residence of high altitudes. Our study revealed that incidence of congenital color vision deficiency is much higher in male children living in high altitudes (i.e., 11.05\%) as compared to that in female children (i.e., 2.24\%) and other areas. It has been noted that individuals with congenital color vision deficiency are less capable at their work than those people with normal color vision [15].

\section{Conclusion}

Congenital color vision deficiency sometimes causes problems at school if colors are used to help with teaching and learning process, problems may arise with identifying the color of fruit, selecting clothes, trouble in identifying safety warnings or signs. Many jobs, such as pathologists, architects, electricians and garment workers, require accurate color identification. More detail study in the larger area should be done in order to find the prevalence of CVD in children in different geographical areas so that in future, such people could avoid certain professions and make their life more comfortable.

\section{Acknowledgements}

I express my deep sense of gratitude to all my participants without their cooperation this study might not have been successful.

\section{References}

1. Barrett KE, Barman SM, Boitano S, Brooks HL (2010) Vision. In: Ganong's Review of Medical Physiology, (23rd edn). Tata McGraw Hill Education Private limited, New Delhi, India.

2. Brich J (1993) Diagnosis of defective colour vision. Oxford Medical Publications, Hong Kong.

3. Dalton J (1798) Extraordinary facts relating to the vision of colors with observations. Memoirs of the Literary and Philosophical Society of Manchester 5: $28-45$.

4. Deeb SS (2006) Genetics of variation in human color vision and the retinal cone mosaic. Curr Opin Genet Dev 16: 301e307.

5. Bruner JS, Pistman L, Rodrighes J (1951) Expectations and the perception of color. Am J Psych 64: 216-227.

6. Duncker K (1939) The influence of past experience on perceptual properties Am J Psychol 52: 255-265.

7. Gnadt GR, Amos JF (1992) Dichromacy and its effect on a young male. J Am Optom Assoc 63: 475-480.

8. Balasundaram R, Reddy SC (2006) Prevalence of colour vision deficiency among medical students and health personnel. Malaysian Family Physician 1: $52-53$.

9. Ishihara S (1917) Tests for color-blindness, Handaya, Hongo Harukicho, Tokyo.

10. Natu M (1987) Colour blindness-A rural prevalence survey. Indian J Ophthal 35: 71-73.

11. Niraula D, Saha CG (2010) The incidence of colour blindness among some school children of Pokhara, West Nepal. Nepal Med Coll J 12: 48-50.

12. Kharel S, Mainalee M, RautB, Dhungana A, Gupta R (2017) Prevalence of congenital colour vision deficiency (CVD) in school children of Bhaktapur Nepal. Int J Med Sci Clin Invn 4: 3137-3139.

13. Shah A, Hussain R, Fareed M, Afzal M (2013) Prevalence of red-green color vision defects among muslim males and females of Manipur, India. Iranian J Publ Health 42: 16-24

14. Benjamin WJ (2006) Borisch's Clinical Refraction, (2nd edn) Butterworth Heinemann an imprint of Elsevier Inc, The Netherlands.

15. Spalding JAB (1999) Color vision deficiency in medical profession. Br J Gen Prac 49: 469-475. 